\title{
Comparative studies of spermatogenesis in fertile and subfertile men
}

\author{
MA LAMONT,* MJW FAED,* AND K BAXBY $\dagger$ \\ From the *Cytogenetics Laboratory, Ninewells Hospital and Medical School, and $\dagger$ Department of Urology, \\ Royal Infirmary, Dundee, UK
}

SUMmARY Testicular biopsy specimens from 16 fertile and 10 subfertile men with normal male karyotype were studied quantitatively to provide histological and cytogenetic data for a basis of reference in assessing abnormalities of spermatogenesis. Histological studies included estimation of the proportion and activity of germinal epithelium and an assessment of tubular morphology. In cytogenetic preparations, counts were made of cells at different stages of meiosis. Studies of cells at diakinesis included chiasma counts and percentage of cells with dissociated sex chromosomes. One fertile and six subfertile men showed decreased germinal activity; the six subfertile men also had decreased MII/MI ratios. Other findings were similar in the two groups.

In the investigation of male subfertility, it is difficult to justify testicular biopsy unless this procedure provides sufficient information. In order to recognise a specimen as abnormal it is necessary to know the range of normal variability and, wherever possible, this range should be expressed in quantitative terms since qualitative assessments of tissues of mixed cellularity are particularly prone to observer bias. ${ }^{1}$

Various methods of quantifying tubular histology have been described. The older literature has been reviewed by Johnsen, ${ }^{2}$ whose own method of rating spermatogenesis provides a profile and an overall score of germinal activity; he obtained values for 17 normal men and, using biopsies from 335 subfertile men, showed how different histological categories may be quantified.

Skakkebaek and Heller $^{3}$ studied the relative frequency of germinal cells at different stages of development in the seminiferous epithelium using Sertoli cells as a constant. Results from 21 volunteers with normal karyotypes and normal sperm counts showed low inter-individual variation. Similar analysis of biopsy specimens from 44 subfertile men with normal karyotypes but much reduced sperm counts showed whether there were reduced numbers of spermatogonia, spermatocytes, or spermatids. ${ }^{4}$ This method was found to be useful for quantitative analysis of spermatogenesis but involves counting cells in about 30 tubules, a time-consuming process for routine use.

Accepted for publication 20 August 1980
Averback and Wight ${ }^{5}$ applied quantitative morphological techniques to biopsy specimens from subfertile men with apparently normal testicular histology, and to controls not complaining of subfertility. Twenty-nine subfertile men had both tangent counts per square millimetre (tubules lying tangentially against the lines of a graticule) and tubular perimeter per unit area, measured with a Quantimet 720, more than double those in 15 controls. They postulated that these findings indicated hypercurvature of the tubules.

Quantitative cytogenetic studies on biopsy specimens from men not complaining of subfertility have been reported by various workers ${ }^{6-8}$ and include counts of cells at different stages of meiosis, chiasma frequency, and sex chromosome dissociation. In all these studies there has been presumption of normality without evidence of fertility.

This paper reports our attempts to establish normal ranges for assessing testicular biopsy specimens by quantitative histological and cytogenetic studies on specimens from 16 fertile men presenting for vasectomy after the completion of their families. Measurements from 10 subfertile men with no recognised cytogenetic abnormality were compared with those from the fertile men.

\section{Material}

POPULATION STUDIED

Fertile group

Men presenting for vasectomy were asked if they 
would be willing to undergo testicular biopsy. The study was approved by the local ethical committee. Where informed permission had been given, a biopsy was taken from the right testis under general anaesthesia immediately before vasectomy. The age range of the 16 men in this group (Table 1) was 26-58 years, with a mean of 35 . Family size varied from one to five children, with a mean of $2 \cdot 4$, but no preoperative seminal analyses were done and paternity was assumed in all cases.

\section{Subfertile group}

Biopsy specimens from 10 subfertile men with azoospermia or moderate to severe oligospermia were examined; all were known to have normal blood karyotypes. The age range in the subfertile men (Table 2) was 20-33 (mean 28.3) years. Five men had azoospermia, one a very low sperm count, two had low counts, and two had moderate oligospermia. The history of infertility ranged from two to seven years. The spouse of one man (patient 26) with moderate oligospermia had had one early abortion. Initial physical examination did not reveal any testicular abnormalities, but later at operation two of the azoospermic men were found to have obliteration of the vasa deferentia.

\section{Methods}

Immediately after removal, biopsy specimens were divided into two. Bouin's fluid was used to fix one portion, which was then embedded in paraffin wax, sectioned at $7 \mu \mathrm{m}$, and stained with haematoxylin and eosin for histological examination. The other portion, for cytogenetic analysis, was placed in a $1 \%$ sodium citrate solution, and preparations were made by the air drying method ${ }^{9}$ and stained with Giemsa or C-banded. ${ }^{10}$

\section{HISTOLOGICAL ANALYSIS}

Tubules were scored for spermatogenic activity according to the method of Johnsen. ${ }^{2}$ Score values from 1 (atrophic tubules) to 10 (complete, normal spermatogenesis) were allocated to 100 tubules from each biopsy, and the mean biopsy score was obtained. The score distribution was plotted to give

Table 1 Histological and cytogenetic analysis of testicular biopsy specimens from 16 fertile men

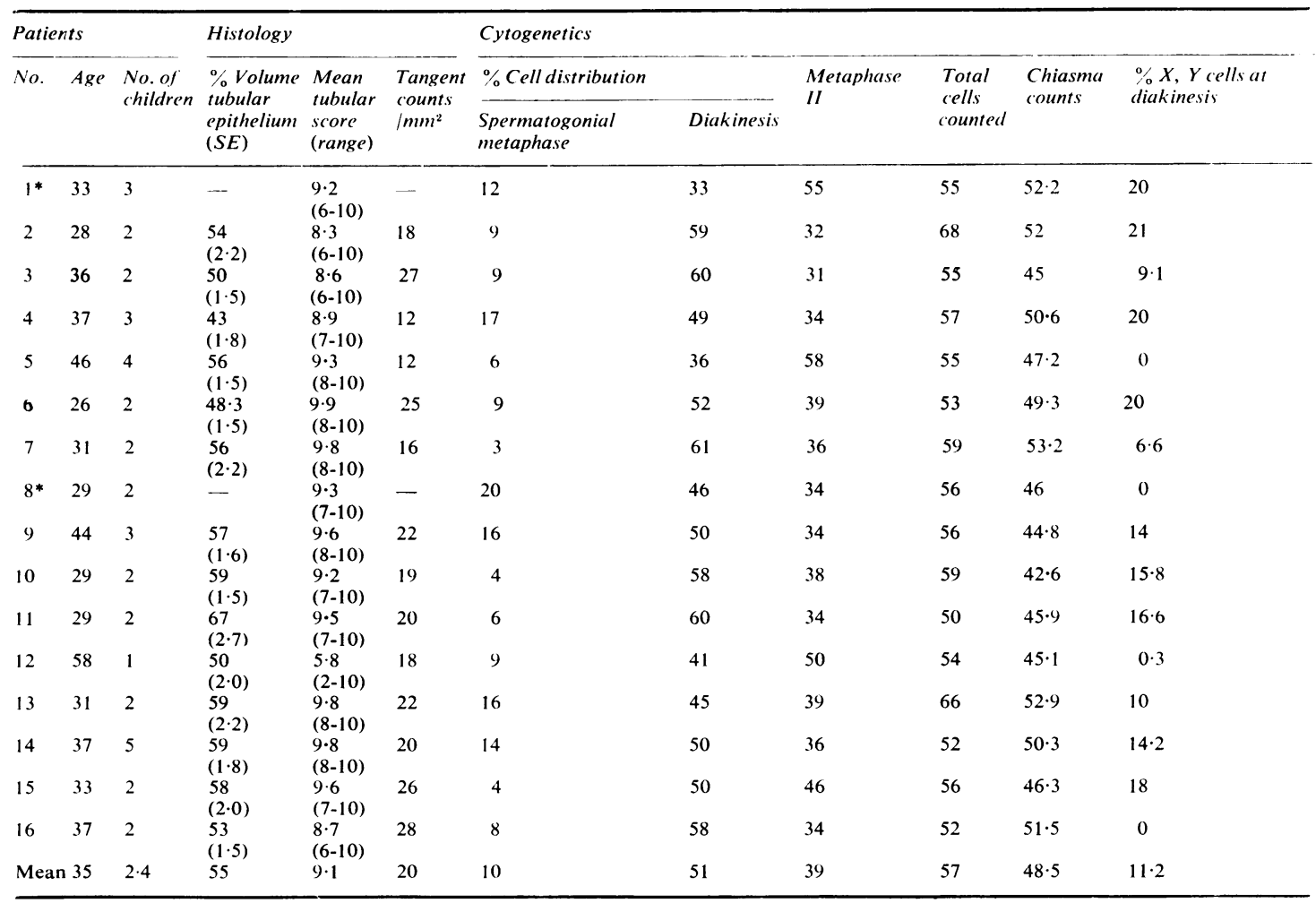

*Specimens from these patients were too small for morphological analysis. 
Table 2 Histological and cytogenetic analysis of testicular biopsy specimens from 10 subfertile men

\begin{tabular}{|c|c|c|c|c|c|c|c|c|c|c|c|}
\hline \multicolumn{3}{|c|}{ Patients } & \multicolumn{3}{|l|}{ Histology } & \multicolumn{6}{|l|}{ Cytogenetics } \\
\hline \multirow[t]{2}{*}{ No. } & \multirow[t]{2}{*}{ Age } & \multirow{2}{*}{$\begin{array}{l}\text { Sperm } \\
\text { counts } \\
\left(\times 10^{\circ} /\right. \\
\mathrm{ml})\end{array}$} & \multirow{2}{*}{$\begin{array}{l}\% \text { Volume } \\
\text { tubular } \\
\text { epithelium } \\
(S E)\end{array}$} & \multirow{2}{*}{$\begin{array}{l}\text { Mean } \\
\text { tubular } \\
\text { score } \\
\text { (range) }\end{array}$} & \multirow{2}{*}{$\begin{array}{l}\text { Tangent } \\
\text { counts } \\
/ \mathrm{mm}^{2}\end{array}$} & \multicolumn{2}{|c|}{$\%$ Cell distribution } & \multirow{2}{*}{$\begin{array}{l}\text { Metaphase } \\
\text { II }\end{array}$} & \multirow{2}{*}{$\begin{array}{l}\text { Total } \\
\text { cells } \\
\text { counted }\end{array}$} & \multirow{2}{*}{$\begin{array}{l}\text { Chiasma } \\
\text { counts }\end{array}$} & \multirow{2}{*}{$\begin{array}{l}\% X, Y \\
\text { cells at } \\
\text { diakinesis }\end{array}$} \\
\hline & & & & & & $\begin{array}{l}\text { Spermatogonial } \\
\text { metaphase }\end{array}$ & Diakinesis & & & & \\
\hline 17 & 32 & 0 & $\begin{array}{l}34 \\
(1 \cdot 5)\end{array}$ & $\begin{array}{l}4 \cdot 0 \\
(1-6)\end{array}$ & 28 & 11 & 70 & 19 & 124 & $47 \cdot 5$ & 8 \\
\hline 18 & 33 & 0 & $\begin{array}{l}31 \\
(1 \cdot 4)\end{array}$ & $\begin{array}{l}3 \cdot 1 \\
(1-10)\end{array}$ & 16 & 10 & 63 & 27 & 50 & $53 \cdot 1$ & 19 \\
\hline 19 & $: 0$ & 0 & $\begin{array}{l}26 \\
(1 \cdot 9)\end{array}$ & $\begin{array}{l}2 \cdot 2 \\
(1-8)\end{array}$ & 22 & 12 & 72 & 16 & 27 & $45 \cdot 4$ & 25 \\
\hline $20^{*}$ & 28 & 0 & $\begin{array}{l}63 \\
(1 \cdot 5)\end{array}$ & $\begin{array}{l}9 \cdot 1 \\
(7-10)\end{array}$ & 18 & 9 & 61 & 30 & 54 & $45 \cdot 4$ & $\mathbf{0}$ \\
\hline $21^{*}$ & 20 & $\mathbf{0}$ & $\begin{array}{l}41 \\
(1 \cdot 5)\end{array}$ & $\begin{array}{l}9 \cdot 6 \\
(8-10)\end{array}$ & 19 & 5 & 51 & 44 & 119 & $50 \cdot 6$ & 12 \\
\hline 22 & 33 & 1 & $\begin{array}{l}31 \\
(2 \cdot 1)\end{array}$ & $\begin{array}{l}5 \cdot 2 \\
(1-8)\end{array}$ & 23 & 12 & 72 & 46 & 186 & 50.3 & 16 \\
\hline 23 & 27 & 5 & $\begin{array}{l}50 \\
(2 \cdot 0)\end{array}$ & $\begin{array}{l}4 \cdot 3 \\
(2-10)\end{array}$ & 25 & 3 & 77 & 20 & 35 & $47 \cdot 0$ & 25 \\
\hline 24 & 33 & 6 & $\begin{array}{l}60 \\
(2 \cdot 8)\end{array}$ & $\begin{array}{l}5 \cdot 6 \\
(2-10)\end{array}$ & 13 & 22 & 61 & 17 & 30 & $53 \cdot 0$ & 8 \\
\hline 25 & 27 & 14 & $\begin{array}{l}47 \\
(2 \cdot 2)\end{array}$ & $\begin{array}{l}8 \cdot 6 \\
(2-10)\end{array}$ & 20 & 11 & 56 & 33 & 57 & $53 \cdot 1$ & $\mathbf{0}$ \\
\hline 26 & 25 & 16 & $\begin{array}{l}57 \\
(1 \cdot 5)\end{array}$ & $\begin{array}{l}9 \cdot 7 \\
(9-10)\end{array}$ & 20 & 16 & 40 & 44 & 80 & $45 \cdot 9$ & 0 \\
\hline
\end{tabular}

*Both these men were subsequently found to have obliterated vasa deferentia.

a profile of testicular activity.

Point counts of tubular epithelium were made using a $\times 10$ objective, over 10 fields where possible, and the percentage volume of tubular epithelium was calculated. ${ }^{11}$ Over the same 10 fields, points where graticule lines lay tangentially against the tubules were counted and the average count per square millimetre was calculated. ${ }^{5}$

\section{CYTOGENETIC ANALYSIS}

Proportions of cells at spermatogonial metaphase, in diakinesis, and metaphase II of meiosis were calculated by examining a minimum of 50 cells where possible.

At diakinesis chiasmata were counted on 10 cells with well-spaced bivalents, and an average was taken for each specimen. $\mathrm{X}, \mathrm{Y}$ bivalents were examined in all well-spread cells at diakinesis, and the percentage dissociation was calculated. Each specimen was also examined, using C-banded preparations, for possible abnormalities of pairing at diakinesis.

\section{Results}

\section{FERTILE MEN}

Table 1 gives the histological and cytogenetic results for the 16 fertile men. Two of the specimens, from cases 1 and 8 , were very small $\left(<2 \mathrm{~mm}^{3}\right)$ and had too much tissue distortion to justify point counting, and in case 11 only three fields were available for analysis.

Tubular epithelium accounted for $43-67 \%$ of total testicular tissue, with a mean of 55 and a standard deviation of 6.8 . Fifteen of the 16 fertile men had sperm present in most tubules, with an overall mean biopsy score $>9$. Figure 1a shows a typical histogram or 'biopsy profile'. The biopsy specimen from patient 12 contained, along with tubules showing full spermatogenesis, $15 \%$ of tubules with Sertoli cells only; the mean score for this patient was $5 \cdot 8$, with a distribution as seen in the histogram (Fig. 1b). Tangent counts were from 12 to $28 / \mathrm{mm}^{2}$.

Cell distribution counts determined on cytogenetic preparations showed $3-20 \%$ cells in spermatogonial metaphase, $33-61 \%$ at diakinesis, and $32-58 \%$ in metaphase II. Chiasma counts per cell

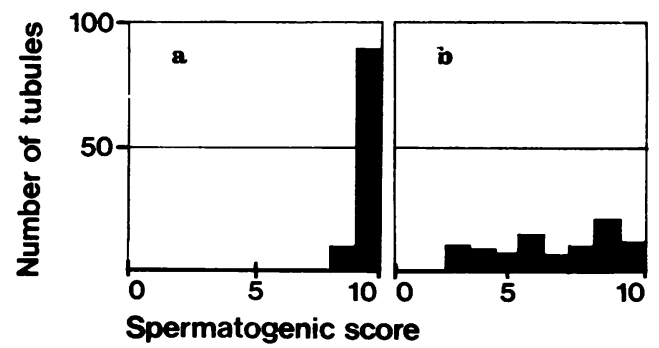

Fig. 1 Tubular spermatogenic biopsy score distribution in fertile men: (a) Patient 6. Spermatogenic biopsy score showing typical distribution with mean score $(M S)>9$ (b) Patient 12. Biopsy score distribution with MS 5.8 
ranged from $42 \cdot 6$ to $53 \cdot 2$ with a mean of $48 \cdot 5$. The percentage of cells showing dissociation of the sex chromosomes at diakinesis ranged from 0 to $26 \%$ (mean $11 \cdot 2 \%$ ).

\section{SUBFERTILE MEN}

Results for the subfertile men are shown in Table 2, with the biopsy profiles for all these patients in Figure 2.

Four biopsy specimens, all from patients from whom seminal analysis showed sperm density of less than $2 \times 10^{6} / \mathrm{ml}$, contained a lower percentage $(<40 \%)$ of tubular epithelium than that seen in specimens from the fertile group; these four biopsy specimens, however, all contained atrophic tubules. The mean tubular scores in these patients were also low, although only one did not have a few tubules containing spermatozoa; in this patient (17) spermatogenesis went no further than the formation of the occasional spermatid.

The other patients with azoospermia $(20,21)$ had biopsy specimens with percentage volumes of epithelium, mean tubular scores, and histograms similar to those of fertile men. Both men were found to have bilateral obliteration of the vasa deferentia.

Both patients $(23,24)$ whose sperm counts were slightly higher but still much reduced at 5 and $6 \times 10^{6} / \mathrm{ml}$ respectively had percentage volumes of tubular epithelium within the normal range but a lowered spermatogenic score. The histogram in each case shows tubules at all stages, from tubules with Sertoli cells only to tubules with full spermatogenesis.

Patients 25 and 26, both with moderate oligospermia, showed no reduction in percentage volume of tubular epithelium. The biopsy score of 8.6 for patient 25 was within the range found in fertile men, but his histogram (Fig. 2) did not show the usual distribution: $10 \%$ of tubules were atrophic or contained only Sertoli cells, or spermatogonia. In patient 26, whose mean tubular score was 9.7, spermatozoa were present in all tubules. All tangent counts were in the range found for biopsy specimens from fertile men.

Cell distribution counts in biopsy specimens from the subfertile men showed the proportion of cells in spermatogonial metaphase to be similar to that in fertile men. Five biopsy specimens had $<30 \%$ of cells in metaphase II, lower than was found in the fertile range. Chiasma counts $(45 \cdot 4-53 \cdot 1$, mean 49) fell within the normal range. None of the specimens showed evidence of autosomal dissociation or of increased $\mathrm{X} / \mathrm{Y}$ dissociation.

Histological and cytogenetic results were compared by plotting biopsy scores against MII/MI ratios (Fig. 3). The overall correlation coefficient, $r$, was $0.49(\mathrm{P}<0.01)$. Biopsy scores for the fertile men were, however, almost all at the upper end of the scale, with MII/MI ratios > 0.5. Results for the infertile men, where both parameters covered a wide range, showed higher correlation, $r=0.8105$ $(P<0.001)$.

\section{Discussion}

H I S T O L O G Y

Theoretically reduction in the volume of germinal epithelium and reduction in spermatogenic activity could account independently for decreased sperm production. A lowered percentage volume of

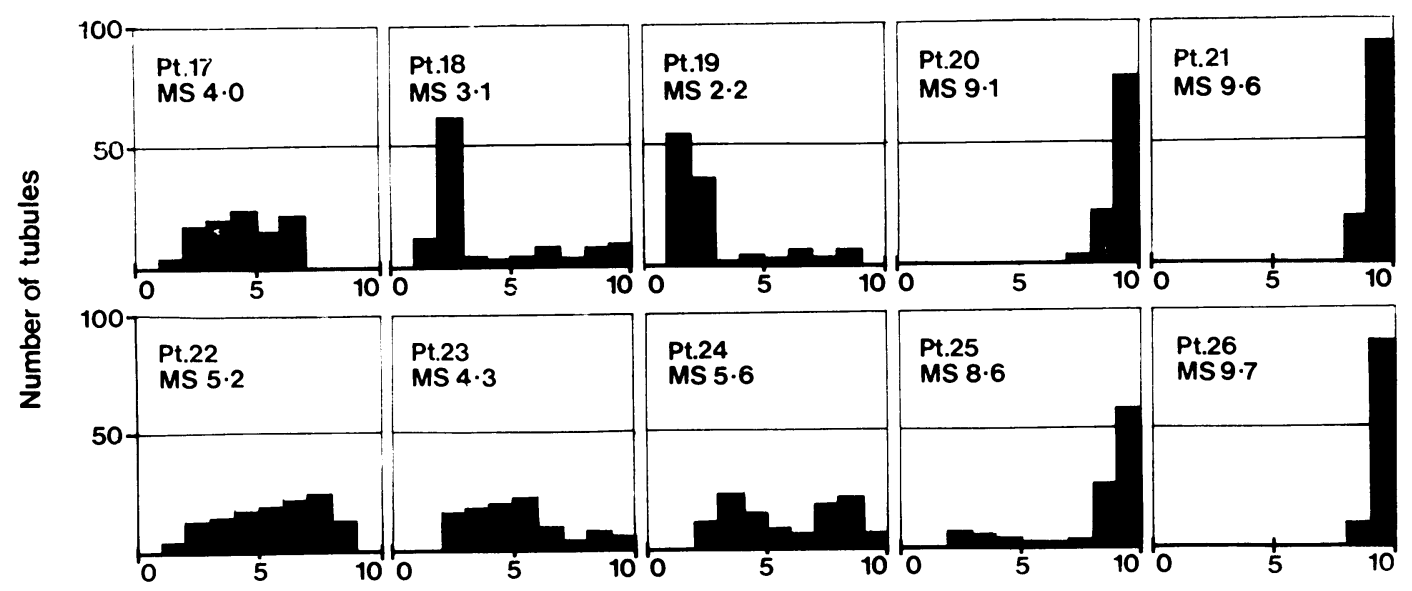

Spermatogenic score

Fig. 2 Tubular spermatogenic biopsy score distribution in 10 subfertile men. 


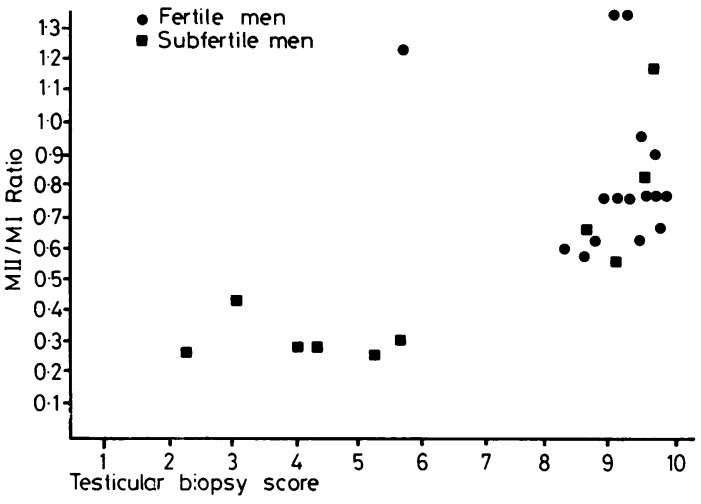

Fig. 3 Mean testicular biopsy score plotted against MII/MI ratio. Overall correlation coefficient, $r=0.49$ ( $\mathrm{P}<0.01)$. Subfertile men-correlation coefficient, $r=0.81(\mathrm{P}<0.001)$.

germinal epithelium, however, was found only in association with tubular degeneration and not as a separate entity. Reduction in spermatogenic activity was associated with both normal and decreased percentage volumes of tubular epithelium. Thus, apart from a decrease in the presence of atrophy, the proportion of germinal epithelium did not give any clear guide to testicular function.

We found mean biopsy scores to be a useful indicator of spermatogenic activity. In the fertile men, with one exception, active spermatogenesis with mature spermatozoa was seen in most tubules; the average biopsy score count was $>9$. The exception, patient 12 , with a biopsy score of $5 \cdot 8$, had a proportion of tubules containing Sertoli cells only. This man, married six years previously at the age of 52, had one child conceived within the first year of marriage. He had no history of disease, either recent or remote, or of any occupational hazard. A request for vasectomy was the reason for his first hospital attendance. No cause was apparent for his testicular pathology. It may have been focal, the small piece of tissue removed at biopsy not being representative of the testis as a whole. He was older than the other men in this series, but Johnsen ${ }^{2}$ found testes from two men aged 54 and from one man aged 60 to have biopsy scores of 9.4 and over.

The normal biopsy scores found in two azoospermic men correlated with the finding of blocked vasa deferentia in these patients. Biopsy scores of the other men with azoospermia or severely depressed sperm counts were low. A biopsy with a low mean score may indicate either a complete spermatogenic arrest at spermatocyte level or that tubules range from complete atrophy to tubules with full normal spermatogenesis. This can be demonstrated by examining the profile of tubular counts. For example, patients 17 and 23 had similar mean biopsy scores; but patient 17 , with no tubules containing spermatozoa, was azoospermic; patient 23 , in whose biopsy specimen $10 \%$ of tubules contained spermatozoa, had a sperm count of $5 \times 10^{6} / \mathrm{ml}$.

In the two men $(25,26)$ with moderate oligospermia, but biopsy scores within the normal range, the lowered sperm count cannot have been due to defective tubular spermatogenesis, and other causes should be sought-for instance, hypercurvature, suggested as a factor leading to oligospermia. ${ }^{5}$ In our study, however, tubular morphology showed no difference between the fertile and subfertile groups. Averback and Wight, ${ }^{5}$ whose report suggested that hypercurvature was a feature of testes of subfertile men, used specimens in which histology was apparently normal; only four specimens from our infertile men, the two mentioned above and the two with a recognised block to sperm transport $(20,21)$, fulfil this criterion. Tangent counts $/ \mathrm{mm}^{2}$ from this limited number of four all fall within the normal range.

\section{CYTOGENETIC ANALYSES}

Skakkebaek et al. ${ }^{7}$ reported meiotic analyses of 18 controls and 18 subfertile men. All 18 controls had MII/MI ratios $>0.5$ but in 11 of the 18 subfertile men the ratio was $<0.5$. Similarly, in our series, none of the fertile men, but six out of 10 subfertile men, had reduced MII/MI ratios. These subfertile men were also the six found to have low biopsy scores. Associated with an overall depression of spermatogenesis there was a delay at the first meiotic division. In contrast, the lowered biopsy score found in the man from the fertile group was not associated with a lowered MII/MI ratio. This man, with mixed testicular histology but normal spermatogenic cell ratios, did not complain of subfertility unlike the six men, also with mixed testicular histology but, in addition, evidence of cytogenetic disturbance.

Chandley et al. ${ }^{12}$ found a correlation between decreased numbers of cells reaching metaphase II and increased percentage of cells with unpaired sex chromosomes, especially when this was over $40 \%$, but in our series the highest frequency of dissociation was $25 \%$ found in two subfertile men; both had low MII/MI ratios.

The concurrent analysis of histological and cytogenetic data provides an overall assessment of testicular findings. In particular, the biopsy score distribution and cytogenetic cell distribution counts may be expected to provide a useful insight into the cause of spermatogenic failure. 
We report elsewhere (unpublished observations) on the application of this approach to the analysis of biopsies from subfertile men with chromosomal abnormalities.

We thank Professor Beck for his advice on the manuscript, Doris McLean for the cytogenetic preparations, the staff of the Pathology Laboratory for the histological slides, and Dorothy Morrison for typing assistance.

\section{References}

${ }^{1}$ Coppleson LW, Factor RM, Strum SB, Graff PW, Rappaport H. Observer disagreement in the classification and histology of Hodgkin's disease. $J$ Nat Cancer Inst 1970;45:731-40.

- Johnsen SC. Testicular biopsy score counts. A method for registration of spermatogenesis in human testes: Normal values and results in 335 hypogonadal males. Hormones $1970 ; 1: 2-25$.

${ }^{3}$ Skakkebaek NE, Heller CG. Quantification of human seminiferous epithelium I. Histological studies in 21 fertile men with normal chromosome complements. J Reprod Fertil 1973;32:379-89.

${ }^{4}$ Skakkebaek NE, Hammen R, Philip J, Rebbe H. Quantification of human seminiferous epithelium III. Histo- logical studies in 44 infertile men with normal chromosome complements. Acta Pathol Microbiol Scand [A] $1973 ; 81: 97-111$.

${ }^{5}$ Averback P, Wight D. Seminiferous tubule hypercurvature: a newly recognised common syndrome of human male infertility. Lancet 1979;1:181-3.

${ }^{6}$ Mcllree ME, Selby Tulloch W, Newsam JE. Studies on human meiotic chromosomes from testicular tissue. Lancet 1966;1:679-82.

${ }^{7}$ Skakkebaek NE, Bryant JI, Philip J. Studies on meiotic chromosomes in infertile men and controls with normal karyotype. J Reprod Fertil 1973;35:23-36.

${ }^{8}$ McDermott A. The frequency and distribution of chiasmata in man. Ann Hum Genet 1973;37:13-20.

${ }^{9}$ Evans EP, Breckon G, Ford CE. An air drying method for meiotic preparations from mammalian testes. Cytogenetics $1964 ; 3: 289-94$

${ }^{10}$ Chandley AC, Fletcher J. Centromere staining at meiosis in man. Hum Genet 1973; 18:247-52.

${ }^{11}$ Dunnill MS. Quantitative methods in histology. In: Dyke SC, ed. Recent advances in clinical pathologv, 1968; Series V:401-6.

${ }^{12}$ Chandley AC, Fletcher J, Watson GS. Cytogenetics and infertility in man. II. Testicular histology and meiosis. Ann Hum Genet 1976;40:165-76.

Requests for reprints to: Dr MA Lamont, Cytogenetics Laboratory, Ninewells Hospital and Medical School, Dundee DD1 9SY. 